\title{
The feminisation of psychiatry: changing gender balance in the psychiatric workforce
}

During the past 40 years, the proportion of women entering UK medical schools has risen from $20 \%$ to a figure predicted to remain stable at 60-65\% (McManus, 1997). This change has been paralleled by increasing numbers of women in the psychiatric workforce. The UK Medical Careers Research Group found that women contributed $37 \%$ of doctors working in psychiatry 3 years after graduation in 1974 compared with 67\% among 1999 graduates (Goldacre et al, 2005). Female doctors have been significantly more likely to select a career in psychiatry than their male counterparts, although there has been a narrowing of this gender gap among more recent cohorts of graduates (Lambert \& Goldacre, 2002). We reflect on why women may preferentially select a career in psychiatry and what implications the 'feminisation' of psychiatry (i.e. the increasing proportion of female psychiatrists) might have for recruitment and workforce planning.

\section{Are women better at psychiatry?}

There is evidence that among medical students, females are better at rating psychopathology than males (Fabrega et al, 1994), although this may decrease after men are fully trained as psychiatrists. However, these data suggest that women have at least an initial advantage in the understanding of mental states. Linked with the finding that psychiatrists are more empathic than colleagues in other specialties (Hojat et al, 2002), this is possibly because women have better 'emotional intelligence', which has been defined as 'a set of skills hypothesised to contribute to the accurate appraisal and expression of emotion, the effective regulation of emotion, and the use of feelings to motivate, plan, and achieve' (Salovey \& Mayer, 1990). Women perform better than men on scales to measure emotional intelligence and it is clear that superior skills in this area would be of benefit to female psychiatrists, perhaps making the specialty more attractive as a career choice.

Females may have more positive attitudes to mental illness, psychiatry and psychiatric patients. The literature on students' attitudes to psychiatry is large but results are slightly inconsistent. Alexander \& Eagles (1986), Calvert et al (1999) and McParland et al (2003) found that female medical students had more positive attitudes to psychiatry than males, and Maidment et al (2003) found that this was also true for female sixth-form students considering careers in medicine. However, Gellaty et al (1995) and Singh et al (1998) found no gender difference in attitudes. No studies have found male undergraduates to harbour more positive attitudes than females.

An Australian study (Rey et al, 2004) found that women psychiatrists suffered fewer formal complaints, threats of legal action and patient suicides, but as was also reported by Rathod et al (2000) in the UK they experienced more work-related stress. Women might therefore deal better with challenging or confrontational clinical situations, but find themselves more affected by the issues involved. Some of the same factors that may make them better psychiatrists (increased empathy, enhanced emotional intelligence and greater sensitivity) might also predispose them to stress.

Gender was not predictive of success in the MRCPsych part I and II examinations (Tyrer et al, 2002). This is at variance with other specialties in medicine where females tend to outperform males in both undergraduate and postgraduate exams (Field \& Lennox, 1996). It is difficult to know whether this apparent difference is related to the females or the males who enter psychiatry.

Hence, women may pursue the specialty because they have innate abilities suited to psychiatry and they may well start with more positive attitudes. Ward (1982) found that women psychiatrists were just as likely as other hospital specialists to pursue their chosen career because of interest in or aptitude for the specialty. Brook (1981) disagreed. He found that women's choice of psychiatry was related to family circumstances and the availability of part-time posts.

\section{Do women choose psychiatry because it fits in better with family life?}

Factors related to lifestyle are known to be important in career choice within the medical profession (Calligaro et al, 2004; Tolhurst \& Stewart, 2004). However, it has not been shown that these factors are more important for 


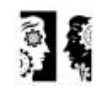

editorial women than men. Parkhouse \& Ellin (1988) and Goldacre \& Lambert (2000) found that there is a net movement of junior doctors into psychiatry from other specialties. Female graduates may decide upon their final career choices later than male doctors (Goldacre \& Lambert, 2000) and Brook (1981) found that family life was an important influence upon this decision. Tait \& Platt (1995) surveyed 2200 female and 200 male consultants in the National Health Service and found that women reached consultant grade at about the same time as their male contemporaries, but were more likely to be working in anaesthetics, radiology, pathology or psychiatry. They had chosen these specialties because they were most compatible with family commitments. Goldacre et al (2005) reported that respondents considered that psychiatry offered better hours and working conditions. Lambert et al (2003) found that new graduates moved away from other hospital specialties, but not psychiatry, because of lifestyle factors. Since most of these studies have not noted gender differences, it is probably sexist to infer that such factors are more important for women than for men who enter psychiatry.

Sexism does exist in medicine and may influence career choice. Although McManus \& Sproston (2000) found no specific evidence for a 'glass ceiling' in medicine, they did conclude that the lack of women consultants provided 'evidence in some cases of disproportionate promotion that is best interpreted as direct or indirect discrimination'. Tait \& Platt (1995) found female consultants were less likely to receive merit awards. Women are underrepresented in medical school faculties (Heslop, 1987) and tend to achieve lower ranks if they pursue academic careers (Leibenluft et al, 1993). Stratton et al (2005) found that although large proportions of medical students had observed or experienced gender discrimination or sexual harassment, females were significantly more likely to describe such experiences as affecting their choice of specialty. This may be most salient in the surgical specialties (Field \& Lennox, 1996). Since more women choose psychiatry it is tempting to suggest that this may relate to less sexism within the specialty, but there is no evidence for this.

\section{Psychiatric workforce planning}

Workforce planning is never simple and attempting to predict possible effects of the 'feminisation' of psychiatry adds to the complexity. If much of the attraction of our specialty relates to working conditions, and if the European Working Time Directive and the Consultant Contract improve these in all specialties, psychiatry will not be as attractive; proportionally fewer women (and men) will enter the specialty and recruitment will fall. The new contract in general practice, another specialty in which females are overrepresented (Lambert \& Goldacre, 2002), could have a similar effect on recruitment into psychiatry. However, were all other factors to remain equal, because more women are entering (expanding) medical schools, there would be more psychiatrists in the longer term. The situation is further complicated by retirement. Eagles et al (2005) found that women consultant psychiatrists in Scotland intend to retire earlier than men, with nearly twice as many females (41\%) planning to finish work on or before their 55th birthday.

Workforce issues relating to pregnancy, children and part-time employment are complex and are outside the scope of this paper. Briefly, although changing expectations of gender roles will give rise to increasing numbers of male doctors seeking to work part-time (Evans et al, 2000), the great majority of part-time doctors are women. When Lambert et al (1996) surveyed 1983 UK graduates, $3 \%$ of men and $45 \%$ of women were working part-time. At least two-thirds of female doctors will have children (Sinden et al, 2003), which is associated with part-time work (Rhodes, 1990) and delay in career advancement, particularly in academic medicine (Carr et al, 1998). Surveys of female doctors in the UK (Evans et al, 2000; Mather, 2001) indicate that there is an underprovision of part-time posts in terms of respondents' preferences. More women work part-time in primary care than in the hospital specialties (Lambert et al, 1996), implying that good provision of part-time training and non-training posts may attract more female psychiatrists. If there are to be more part-time posts, then more trainees will be required to maintain an adequate supply of consultants (Mather, 2001).

The specialty of obstetrics and gynaecology seems to parallel psychiatry in that juniors face difficulties related to pregnancy (Phelan, 1988), there are too few entrants, most of the existing doctors are women, and there are calls for measures to increase recruitment (Higham \& Steer, 2004; Bienstock \& Laube, 2005), although gender imbalance seems further advanced than in psychiatry. The situation seems so acute that Higham \& Steer (2004) felt it necessary to caution that excluding men from obstetrics is 'fundamentally unwise'. Could the same be said for psychiatry?

Goldacre et al (2004) found that teachers at medical school were important determinants of career choice and that positive role models of the same gender tend to enhance recruitment (Park et al, 2005). If in the future good teachers are more likely to be female then it is conceivable that the specialty will become less attractive to male graduates.

However, we consider the advantages of the increasing numbers of women in psychiatry to greatly outweigh the possible disadvantages. With a little reluctance, we as male authors accept the evidence that women, in terms of their abilities and attitudes, are collectively better predisposed to become psychiatrists than their male counterparts. The historical keenness of women to become psychiatrists should be fostered with further female-friendly policies and attitudes, but it will be important to factor gender differences (most notably pregnancies, part-time working and earlier retirement) into the equations underlying workforce planning.

\section{Declaration of interest}

None. 


\section{Acknowledgement}

We thank Lana Hadden for secretarial support.

\section{References}

ALEXANDER, D. A. \& EAGLES, J. M. (1986) Attitudes of men and women medical students to psychiatry. Medica Education, 20, 449-455.

BIENSTOCK, J. L. \& LAUBE, D.W. (2005) The recruitment phoenix: strategies fo attracting medical students into obstetrics and gynecology. Obstetrics and Gynecology, 105, 1125-1127.

BROOK, P. (1981) The choice of career of consultant psychiatrists. British Journal of Psychiatry, 138, 326-328.

CALLIGARO, K. D., DOUGHERTY, M. J., SIDAWY, A. N., et al (2004) Choice of vascular surgery as a specialty; survey of vascular surgery residents, general surgery chief residents, and medical students at hospitals with vascular surgery training programs. Journal of Vascular Surgery, 40, 978-984.

CALVERT, S. H. S., SHARPE, M., POWER, M., et al (1999) Does undergraduate education have an effect on Edinburgh medical students' attitudes to psychiatry and psychiatric patients? Journal of Nervous and Mental Disease, $187,757-761$

CARR, P. L., ASH, A. S., FRIEDMAN R. H., et al (1998) Relation of family responsibilities and gender to the productivity and career satisfaction of medical faculty. Annals of Internal Medicine, 129, 532-538.

EAGLES, J. M., ADDIE, K. \& BROWN,T. (2005) Retirement intentions of consultant psychiatrists. Psychiatric Bulletin, 29, 374-376.

EVANS, J., GOLDACRE, M. J. \& LAMBERT, T.W. (2000) Views of UK medical graduates about flexible and part-time working in medicine: a qualitative study. Medical Education 34, 355-362

FABREGA, H., ULRICH, R. \& KESHAVAN M. (1994) Gender differences in how medical students learn to rate psychopathology. Journal of Nervous and Mental Disease, 182, 471-475.

FIELD, D. \& LENNOX, A. (1996) Gender in medicine: the views of first and fifth year medical students. Medical Education, 30, 246-252.

GELLATY, C. A., SCHRADER, G. D., CHESTERMAN, H. M., et al (1995) Medical student attitudes to psychiatry; lack of effect of hospital experience. Medical Education, 29 447-451.

GOLDACRE, M. J. \& LAMBERT,T.W. (2000) Stability and change in career choices of junior doctors: postal questionnaire surveys of the United Kingdom qualifiers of 1993. Medical Education, 34, 700-707.

GOLDACRE, M. J., TURNER, G. \& LAMBERT,T.W. (2004) Variation by medical school in career choices of UK graduates of 1999 and 2000 . Medical Education, 38, 249-258.

GOLDACRE, M. J., TURNER, G., FAZEL,

$S$, et al (2005) Career choices for psychiatry: national surveys of graduates of 1974-2000 from UK medical schools. British Journal of Psychiatry, 186, 158-164.

HESLOP, B. F. (1987) For better or worse? Women doctors at the end of the decade. New Zealand Medical Journal, 100, 176-179.

HIGHAM, J. \& STEER, P. J. (2004) Gender gap in undergraduate experience and performance in obstetrics and gynaecology; analysis of clinical experience logs. BMJ, 328, 142-143.

HOJAT, M., GONNELLA, J. S., NASCA T. J., et al (2002) Physician empathy: definition, components, measurement, and relationship to gender and specialty. American Journal of Psychiatry, 159, 1563-1569.

LAMBERT, T.W. \& GOLDACRE, M. J. (2002) Career destinations and views in 1998 of the doctors who qualified in the United Kingdom in 1993. Medical Education, 36, 193-198.

LAMBERT, T.W., GOLDACRE, M. J., PARKHOUSE, J., et al (1996) Career destinations in 1994 of United Kingdom medical graduates of 1983: results of a questionnaire survey. BMJ, $\mathbf{3 1 2}$

893-897.

Region. Psychiatric Bulletin, 24

$133-136$

LAMBERT T.W., DAVIDSON, J.M. EVANS, J., et al (2003) Doctors' reason for rejecting initial choices of specialties as long-term careers. Medical Education, 37, 312-318.

LEIBENLUFT, E., DIAL,T. H., HAVILAND, M. G., et al (1993) Sex differences in rank attainment and research activities among academic psychiatrists.

Archives of General Psychiatry, 50 896-904.

MAIDMENT, R., LIVINGSTON, G. KATONA, M., et al (2003) Carry on shrinking: career intentions and attitudes to psychiatry of prospective medical students. Psychiatric Bulletin 27, 30-32.

MATHER, H. M. (2001) Specialist registrars' plans for working part time as consultants in medical specialties: questionnaire study. BMJ, 322, 1578-1579.

McMANUS, C. (1997) Medical careers: stories of a life. Medical Education, $\mathbf{3 1}$ 31-35.

MCMANUS, I. C. \& SPROSTON, K. A. (2000) Women in hospital medicine in the United Kingdom: glass ceiling, preference, prejudice or cohort effect?

Journal of Epidemiology and Community Health, 54, 10-16.

MCPARLAND, M., NOBLE, L. M., LIVINGSTON, G., et al (2003) The effect of a psychiatric attachment on students' attitudes to and intention to pursue psychiatry. Medical Education 37, 447-454.

REY, J. M., WALTER, G. \& GIUFFRIDA, M. (2004) Australian psychiatrists today: proud of their profession but stressed and apprehensive about the future. Australian and New Zealand Journal of Psychiatry, 38, 105-110.

RHODES, P. (1990) Medical women in the middle: family or career? Periods not working and part-time work amongst women doctors who qualified in 1974 and 1977. HealthTrends, 22 $33-36$.

SALOVEY, P. \& MAYER, J. D. (1990) Emotional intelligence. Imagination, Cognition and Personality, 9, 185-211.

SINDEN, N., SHERRIFF, J. M.,

WESTMORE, S. E. L., et al (2003) Patterns of child-bearing behavior amongst female hospital doctors and GPs. Family Practice, 20, 486-488.

SINGH, S. P., BAXTER, H., STANDEN, P., et al (1998) Changing the attitudes of 'tomorrow's doctors' towards mental illness and psychiatry; a comparison of two teaching methods. Medical Education, 32, 115-120.

STRATTON,T. D., MCLAUGHLIN, M. A., WITTE, F. M., et al (2005) Does students'exposure to gender discrimination and sexual harassment in medical school affect specialty choice and residency program selection? Academic Medicine, 80, 400-408.

TAIT, A. \& PLATT, M. J. (1995) Women consultants, their background and training: some myths explored. Medical Education, 29, 372-376.

PARK, J., MINOR, S., TAYLOR, R. A., et al TOLHURST, H. M. \& STEWART, S. M. (2005) Why are women deterred from (2004) Balancing work, family and general surgery training? American Journal of Surgery, 190, 141-146.

PARKHOUSE, J. \& ELLIN, D. J. (1988) Reasons for doctors' career choice and change of choice. BMJ, 296 1651-1653

PHELAN, S.T. (1988) Pregnancy during residency. I. The decision'to be or not to be'. Obstetrics and Gynecology, 72 425-431.

RATHOD, S., ROY, L., RAMSAY, M., et al (2000) A survey of stress in psychiatrists working in the Wessex other lifestyle aspects: a qualitative study of Australian medical students. Medical Journal of Australia, 181 $361-364$

TYRER, S. P., LEUNG, W. C., SMALLS, J., et al (2002) The relationship between medical school of training, age, gender and success in the MRCPsych examinations. Psychiatric Bulletin, 26 257-263.

WARD, A.W. (1982) Women in psychiatry. British Journal of Psychiatry, $141,202-207$

*Sam Wilson Clinical Teaching Fellow, University of Aberdeen Medical School, Foresterhill, Aberdeen AB25 2ZD, email: sam.wilson@abdn.ac.uk, John M. Eagles Consultant Psychiatrist, Royal Cornhill Hospital, Cornhill Road, Aberdeen $\mathrm{AB} 25 \mathrm{ZZH}$ 